
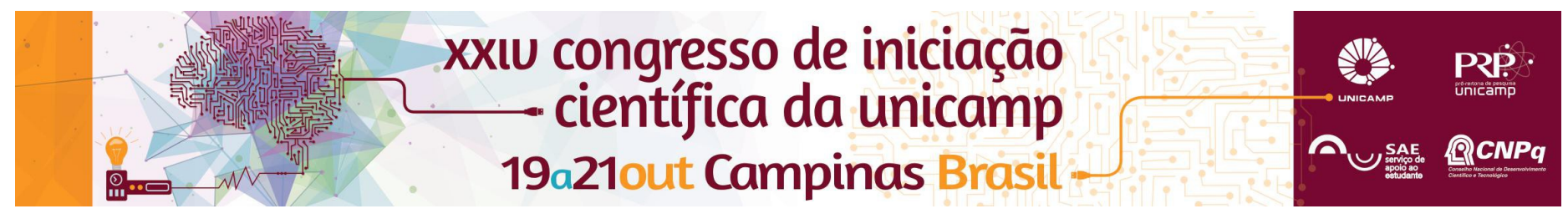

\title{
Cribriform adenocarcinoma of the tongue and minor salivary glands: importance of reclassification and presentation of atypical behavior in broad follow up
}

\author{
Renata F. Varanda*, Louyse V. Carvalho, Marcelo B. Correa, Oslei P. de Almeida, Márcio A. Lopes, Albina \\ Altemani, Fernanda V. Mariano.
}

\begin{abstract}
This work shows the importance of the reclassification of a group of Polymorphous low grade adenocarcinoma (PLGA) to Cribriform adenocarcinoma of the tongue and minor salivary glands (CATMSG) and present a report of a case of this entity, with an unknown behavior, with a large following.
\end{abstract}

\section{Key words:}

Cribriform Adenocarcinoma of the Tongue and Minor Salivary Glands, Histopathological Reclassification, Behavior.

\section{Introduction}

Cribriform adenocarcinoma of the tongue and minor salivary glands (CATMSG) is an entity described in 1999, previously diagnosed (most of the cases reviewed) as polymorphous low grade adenocarcinoma (PLGA). The tongue is the main primary site and believed it to be the only one, but were confirmed new cases in different parts of the oral cavity. The similarities observed in more than 40 patients are described: presence initial cervical metastasis or progression of the disease; morphology resembling the solid and follicular variants of papillary thyroid carcinoma. OBJECTIVE: To show the importance of the reclassification of a group of PLGA to CATMSG and present an unknown behavior of the new entity with a large following.

\section{Results and Discussion}

REPORT: Male, 78 years old, with ulcerated mass in the left soft palate, measuring $5 \mathrm{~cm}$ diameter with unknown outcome. The diagnosis of biopsy was PLGA and after clinical staging, the patient underwent partial maxillectomy. Histopathological examination of the surgical specimen showed neoplasm composed of a single cell type, infiltrating and without capsule, consisting primarily of solid and papillary structures. The tumor parenchyma was divided by fibrous septa and nests formed sometimes were separated from the surrounding fibrous stroma by slots (presumably artifactual), giving a glomerulóide appearance. The nuclei showed often overlapping each other, and pale with frosted glass appearance. Lightweight cellular atypia and no mitosis were observed, while the nucleoli were inconspicuous. The patient developed eight metastases over the 11 years of evolution (cervical and regional) and died of other causes, but with the presence of disease. Conclusion: To the best of our knowledge, the first time present the aggressive nature still unknown this new entity with extensive monitoring corroborating the understanding of this neoplasm. Moreover, this case shows the importance of the reclassification of tumors.

\section{Conclusions}

To the best of our knowledge, we present, by the first time, the aggressive behavior, still unknown, of this new entity with extensive monitoring, corroborating to the understanding of this neoplasm. Moreover, this case shows the importance of the reclassification of tumors.

\section{Acknowledgment}

The authors would like to thank Ana Cláudia Sparapani Piazza, Arethusa Souza, Fabiana Cassarotti and Luzia Magalhães Alves for their technical assistance.

\section{This study was supported by grant: \\ FAPESP PROCESS: 2011/23204-5; \\ FAPESP PROCESS: $2011 / 23366-5$ \\ FAPESP PROCESS: 2015/21922-9 \\ Coordination for the Improvement of Higher Education Personnel (CAPES-PNPD)}

\section{Conflict of interest disclosure}

The authors declare that they have no conflict of interest.

\footnotetext{
1-Michal M, Skálová A, Simpson RH et al. Cribriform adenocarcinoma of the tongue: a hitherto unrecognized type of adenocarcinoma characteristically occurring in the tongue. Histopathology 1999; 35: 495-501.
}

2-Michal M, Kacerovska D, Kazakov DV. Cribriform adenocarcinoma of the tongue and minor salivary glands: a review. Head Neck Pathol 2013; 7 Suppl 1: S3-11.

3-Simpson RH, Skálová A, Di Palma S, Leivo I. Recent advances in the diagnostic pathology of salivary carcinomas. Virchows Arch 2014; 465: 371 384.

4-Skalova A, Sima R, Kaspirkova-Nemcova J, et al. Cribriform adenocarcinoma of minor salivary gland origin principally affecting the tongue: characterization of new entity. Am J Surg Pathol 2011; 35: 1168-1176.

5-Gnepp DR. Salivary gland tumor "wishes" to add to the next WHO Tumor Classification: sclerosing polycystic adenosis, mammary analogue secretory carcinoma, cribriform adenocarcinoma of the tongue and other sites, and mucinous variant of myoepithelioma. Head Neck Pathol 2014; 8: 42-49.

6-Perez-Ordonez B, Linkov I, Huvos AG. Polymorphous low-grade adenocarcinoma of minor salivary glands: a study of 17 cases with emphasis on cell differentiation. Histopathology 1998; 32:521-529.

7-Colmenero CM, Patron M, Burgueno M, Sierra I. Polymorphous low-grade adenocarcinoma of the oral cavity. A report of 14 cases. J Oral Maxillofac Surg 1982; 50: 595-600.

8-Yajima M, Yamazaki T, Minemura T, Kotani A. Tubular adenocarcinoma of the apex of the tongue. J Oral Maxillofac Surg 1989; 47: 86-88. 